\title{
ACL surgical innovation cycles: what goes around, comes around
}

\author{
Robin Martin, ${ }^{1}$ John Nyland, ${ }^{2}$ Roland Peter Jakob ${ }^{3}$
}

${ }^{1}$ Department of Orthopedic Surgery and Traumatology, Lausanne University Hospital, Lausanne, Switzerland ${ }^{2}$ Athletic Training Program, Kosair Charities College of Health and Natural Sciences, Spalding University, Louisville, Kentucky, USA

${ }^{3}$ University of Bern, Bern, Switzerland

Correspondence to Dr Robin Martin, Orthopedics, Lausanne University Hospital, Lausanne 1011, Switzerland; robin.martin@chuv.ch

Received 20 August 2020 Revised 13 October 2020 Accepted 16 October 2020

\section{Linked}

- http://dx.doi.org/10.1136/ jisakos-2020-000544

Check for updates

(C) International Society of Arthroscopy, Knee Surgery and Orthopaedic Sports Medicine 2020. No commercial re-use. See rights and permissions. Published by BMJ.

To cite: Martin R, Nyland J, Jakob RP. J ISAKOS

2020:5:334-341.

\section{ABSTRACT}

Over the past 45 years, the 'gold standards' for ACL surgery have evolved considerably. Many discoveries in the field of $A C L$ surgery seem to come and go, in cycles. The aim of this paper was to confirm these cyclic phenomena by methodically researching the ACL literature. It proposes a bibliometric research of the literature over the last 45 years to assess temporal changes in publications on 3 topics of high interest in ACL surgery for which we hypothesised a cycle phenomenon: surgery to address anterolateral knee instability, $A C L$ repair and prosthetic $A C L$ reconstruction grafts. We searched PubMed from 1975 to 2019 with different equations and different Boolean operators. Review results are presented as graphs depicting the evolution of the annual publication number over the total number of PubMed results that year. Graph analysis confirmed cycles of interest in these 3 fields. When this analysis was put into perspective with the major historical articles in each field, cycles seem to have 5 typical phases: hope, inflation, disillusion, eclipse and rebirth. The initial hope-inflation and rebirth phase trend peak interval was approximately 35 years. Rebirth trend peak slope trajectories for each topic seemed to display more rapid and stronger rise times than the initial trend peak slope trajectories. These cyclic phenomena that were observed suggest that knee surgeons need to better balance early enthusiasm and hope for innovative surgical practice efficacy with the guidance of both scientific rigour derived evidence and history.

\section{INTRODUCTION}

Since the 1960s, orthopaedic surgeons have been searching for the best ACL restoration method. Over the past 45 years, the 'gold standards' for ACL surgery have evolved considerably. As in other orthopaedic subspecialties, surgeons have been positive and enthusiastic about new concepts. Many discoveries seem to come and go in cycles with somewhat consistent characteristics.

A typical cycle includes: Hope: where a new concept raises interest with 'landmark' publication. However, with this we tend to jump too early, accepting unproven conclusions, often forgetting the need for scientific rigour. This is followed by Inflation: where the concept is quickly embellished by a number of supportive 'follower' papers. ${ }^{1}$ After this, Disillusion: where over time, the new concept does not appear to be as promising as expected based on early hype. This is followed by an Eclipse: where surgeons jump to another concept in hopes of identifying another 'knight in shining armour' that may better stand the test of time. Lastly, Rebirth: during which a subsequent generation of orthopaedic surgeons rediscover the initial concept. The aim of this paper was to confirm this cyclic phenomena by methodically researching the ACL literature. We present a historical bibliometric analysis that graphically assesses temporal changes in publications on three topics related to ACL surgery from 1975 through 2019. The analysis will then be put into perspective with the major historical articles.

\section{MATERIALS AND METHODS}

\section{Study design: a historical bibliometric analysis}

We hypothesised three subjects to have sustained a cyclic phenomenon of interest in ACL surgery: surgical procedures to address anterolateral knee instability, ACL repair and synthetic ACL reconstruction grafts. These three topics were selected as in our opinion they presented the highest interest and motivated changes in clinical practice in ACL surgery over the last decades. For each topic we performed separate PubMed searches from 1975 to 2019 with different equations: different terms, combined with different Boolean operators (AND, OR, NOT). MeSH (Medical Subject Headings) terms were included. Truncating search terms were analysed as well. For each query, PubMed provided the total number of citations, as well as the number of citations/year. Yearly count for each query was obtained by adding 'AND year (DP)' to the PubMed query ([DP]: search field for Publication Date). As there is an increase of publications each year for all subjects, the interest for a subject had to be interpreted in the light of the total number of publications as citations increase in all fields each year. This total is available on: https://www.nlm.nih.gov/bsd/ medline_cit_counts_yr_pub.html. Review results are presented as graphs depicting the evolution of the annual publication number over the total number of PubMed results that year, multiplied by $100000 .^{2}$

Preliminary analysis of the literature on PubMed between 1945 and 1975 following the equations described below has shown that the number of publications indexed over that period was negligible (anterolateral instability $n=0 / 460$; ACL repair $\mathrm{n}=13 / 2546$; synthetic ACL reconstruction grafts $n=4 / 651$ ). Therefore, the decision was made to exclude that time period from data analysis.

\section{Data collection}

To analyse interest for surgical procedures in anterolateral knee instability, we used the following equation:

('anterolateral'(All Fields) OR 'anterolateral$l y^{\prime}($ All Fields)) AND ((('“knee’(MeSH Terms) OR 


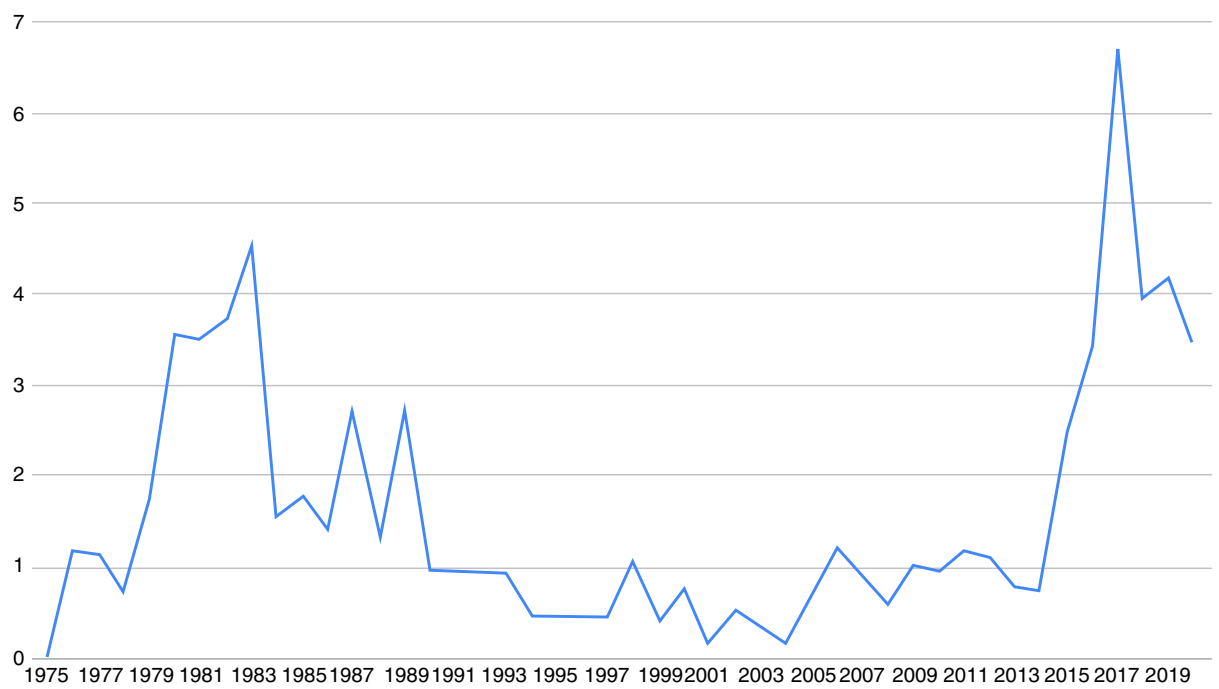

Figure 1 Temporal trends in publications on surgical procedures to address anterolateral instability.

'knee'(All Fields)) OR 'knee joint'(MeSH Terms)) OR ('knee'(All Fields) AND 'joint'(All Fields))) OR 'knee joint'(All Fields)) AND (('instabilities'(All Fields) OR 'instability'(All Fields)) OR 'instable'(All Fields)). For ACL repair, we used the following equation: ('REPAIR'(All Fields) OR 'STABILIZATION'(All Fields)) AND ((('anterior cruciate ligament'(MeSH Terms) OR (('anterior'(All Fields) AND 'cruciate’(All Fields)) AND 'ligament'(All Fields))) OR 'anterior cruciate ligament'(All Fields)) OR 'acl'(All Fields)). Finally, for synthetic ACL reconstruction grafts we used the following equation: '(()((('polyethylene terephthalates'(MeSH Terms) OR ('polyethylene'(All Fields) AND 'terephthalates'(All Fields))) OR 'polyethylene terephthalates'(All Fields)) OR 'dacron'(All Fields)) OR 'LAD'(All Fields)) OR 'LARS'(All Fields)) OR 'polyethylene terephthalate'(All Fields)) OR ('silk'(MeSH Terms) OR 'silk'(All Fields))) AND ((('ligament s'(All Fields) OR 'ligaments'(MeSH Terms)) OR 'ligaments'(All Fields)) OR 'ligament'(All Fields))'

\section{RESULTS AND DISCUSSION}

\section{Temporal trends in research production}

Surgical procedures to address anterolateral instability

A total of 460 citations was identified on PubMed with the annual distribution displayed in figure 1 .

In viewing figure 1 , the reader can observe an example of the Hope component during the late 1960s, early 1970s in the Lemaire $^{3}$ procedure using a strip of the iliotibial band (ITB), as described in the French literature in 1967. In 1976, Macintosh ${ }^{4}$ described the use of an ITB loop behind the lateral intermuscular septum. Also in 1976, Hughston et al identified the middle third lateral capsular ligament attached proximally to the lateral epicondyle and distally to the tibial joint margin. They reported that sectioning this lateral capsular ligament resulted in a major increase of anterolateral rotatory instability. ${ }^{5}$ In 1978, Losee et $a l^{6}$ also using the ITB, described use of a tunnel created at the femoral lateral collateral ligament (LCL) attachment, exiting at the level of the lateral gastrocnemius tendon.

From these initial reports, the concept was then embellished by several 'follower' papers in the late 1970s and early 1980 s demonstrating Inflation. In 1979, Norwood et $a l^{7}$ analysed 36 patients with anterolateral rotatory instability. They reported that isolated ACL injury was only present in four patients, while concomitant lateral structure injury (from lateral capsule to iliotibial tract) was present in 26 patients. In 1979, Ellison et al ${ }^{8}$ described ACL reconstruction associated with an osteotomy of Gerdy's tubercle. In 1983, Andrews et al ${ }^{9}$ described an anterolateral 'mini-reconstruction' by advancing the ITB. In 1986, Zarins and Rowe ${ }^{10}$ reported a combined anterolateral capsule and ACL reconstruction using the ITB and the semitendinosus tendon. In 1986, Terry et $\mathrm{al}^{11}$ in an anatomical study described the detailed anatomy of the capsulo-osseous layer of the ITB tract. In 1987, Lerat et $\mathrm{al}^{12}$ reported a combined anterolateral capsule and ACL reconstruction using the lateral third of the patellar tendon and a strip of the quadriceps tendon. In 1987, Irvine et al ${ }^{13}$ presented a detailed anatomical study of the anterior band of the LCL.

During the late 1980s and early 1990s, Disillusion became manifest as the initial concept did not appear to withstand the test of time. During this period there were a growing number of reports suggesting that extra-articular tenodesis techniques resulted in failure, particularly when performed as an isolated procedure. In 1994, Neyret et al ${ }^{14}$ reported failures using the isolated Lemaire technique. Reports from the early 1990s did not show any clear advantage of combined procedures over isolated intra-articular reconstruction. ${ }^{15} 16$ However, around 1990 it was shown that extra-articular lateral tenodesis could decrease ACL graft loads, possibly reducing the rerupture risk. ${ }^{17}$ In 1987 and 1991, Roth et $a l^{19}$ and O'Brien et $a l^{16}$ reported secondary lateral knee compartment degenerative changes following extraarticular ACL reconstruction using the ITB. In 2011 Dodds et $a l^{20}$ reported that extra-articular tenodesis alone did not restore normal kinematics in the presence of intra-articular ACL deficiency.

The Eclipse of this early extra-articular ACL repair procedure began in the early 1990s and continued through 2012 with the onset of exclusively intra-articular surgical procedures with the arthroscope entering operating rooms. Was it primarily the arthroscope, for example, the pressure to perform the entire surgery arthroscopically that threw the extra-articular anterolateral capsule reinforcement overboard?

The Rebirth of extra-articular anterolateral knee capsule augmentation started in 2012 and is ongoing. There has been 
a rediscovery of the essential anatomy of this region with 'landmark' publications in 2012 including that of Vincent et $a l^{21}$ which reported that anterolateral ligament (ALL) fibres merge with the lateral meniscus and Tanaka $e t a l^{22}$ which reported that the ALL is only a part of the anterolateral capsulo-ligamentous complex. In 2013, Claes et $a l^{23}$ reported that the ALL inserts between Gerdy's tubercle and the fibular head in addition to describing meniscotibial and meniscofemoral bundles. In 2016, Kittl et $a^{24}$ reported that the capsulo-osseous ITB layer provided a major knee rotatory stability function. Others have described the femoral ALL attachment as being somewhat variable, inserting either posteroproximally or anterodistally to the femoral origin of the LCL. ${ }^{23} 25$

The rapid adoption of new 'anatomic ALL reconstruction' surgical techniques suggests the Inflation phenomenon. The literature supports this with the work of Helito et $a l^{26}$ and Smith et $a l^{27}$ in 2015, and Sonnery-Cottet et $a l^{28}$ and Wagih and Elguindy ${ }^{29}$ in 2016. At this point in time new ALL reconstruction techniques are being adopted without having ever been studied in a biomechanics laboratory. To date, no clinical trials have directly compared ALL reconstruction with lateral extraarticular tenodesis procedures. ${ }^{30}$ Biomechanical studies suggest that the ITB might be the most important restraint to internal rotation and that the ALL is of little importance. ${ }^{24}$

\section{ACL repair}

We identified 2533 citations (figure 2).

Hope in the form of successful ACL repair initially began in the late 1930s and continued through the 1960s. Palmer in $1938^{31}$ and O'Donoghue ${ }^{32}$ in 1950 advocated ACL repair early following injury when it was possible to restore anatomical conditions. Many 'followers' embellished the initial concept contributing to Inflation during the 1970s and 1980s. These publications led to open primary ACL repair becoming the preferred technique for the treatment of ACL injuries over this period with good short-term results. The reader is referred to the works of England ${ }^{33}$ and Feagin and Curl ${ }^{34}$ in 1976, Macintosh in 1976-1977, ${ }^{45}$ Marshall et $a l^{36}$ in 1979, Lysholm et $a l^{37}$ in 1982, Warren ${ }^{38}$ in 1983, Odensten et al ${ }^{39}$ in 1985 , Weaver et $a l^{40}$ in 1985 and Sherman and Bonamo ${ }^{41}$ in 1988.

In the late 1980s and early 1990s Disillusion with primary ACL repair set in with reports demonstrating that repair using the techniques of the day did not stand the test of time. Follow-up studies of open repair at mid-term to long-term demonstrated concerning failure rates and high postoperative morbidity (pain, stiffness and instability). The reader is referred to the works of Engebretsen $e t \mathrm{al}^{42}$ in 1989, Feagin and Curl ${ }^{43} 44$ in 1990 and 1996 (reporting rerupture rates of $>50 \%$ at 5 years), Kaplan et $a l^{45}$ in 1990 and Sherman et $a l^{46}$ in 1991 who reported that mid-substance ACL tears had poorer results than proximal tears.

The Eclipse of primary ACL repair continued through the 1990s through 2013. This abandonment largely occurred because several prospective randomised trials favoured ACL reconstruction to repair ${ }^{174748}$ and arthroscopic surgery had largely replaced open ACL repair methods. Additionally, ACL reconstruction could be more easily scheduled in contrast to ACL repair which needed to be performed acutely to maintain anatomical characteristics. Likewise, the rehabilitation protocols of the day focused solely on ACL reconstruction. These factors contributed to leave ACL repair behind with many unanswered questions regarding its true potential.

From 2013 to the present we have seen a Rebirth of interest in primary ACL repair, particularly with use of some form of internal support to facilitate the healing process. Factors associated with this renewed interest include preservation of native ACL proprioceptors that drive the neuromuscular control of dynamic knee stability, native anatomy restoration, developing support for orthobiological tissue healing factors, less surgical morbidity and preservation of other knee joint region tissues for revision purposes if necessary. With this Rebirth attempts are being made to improve outcomes and reduce rerupture rates compared with historical repair and even reconstruction procedures. Innovative surgeons and industry are promoting new arthroscopic surgical techniques and instrumentation. Readers are referred to the landmark work of Kohl et al ${ }^{49}$ who described a dynamic intraligamentary stabilisation technique in 2013, Biercevicz et al $l^{50}$

Results per 100,000 citations in PubMed

proportion for each search by year, 1975 to 2020

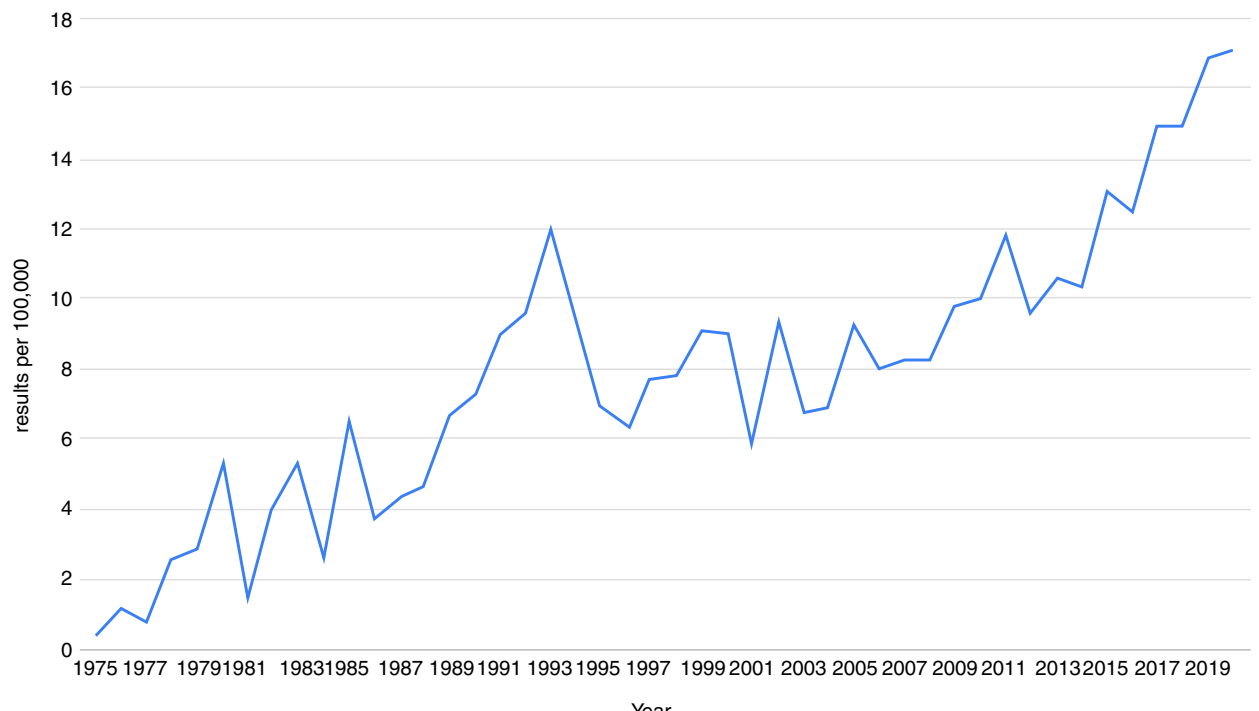

Figure 2 Temporal trends in publications on ACL repair. 


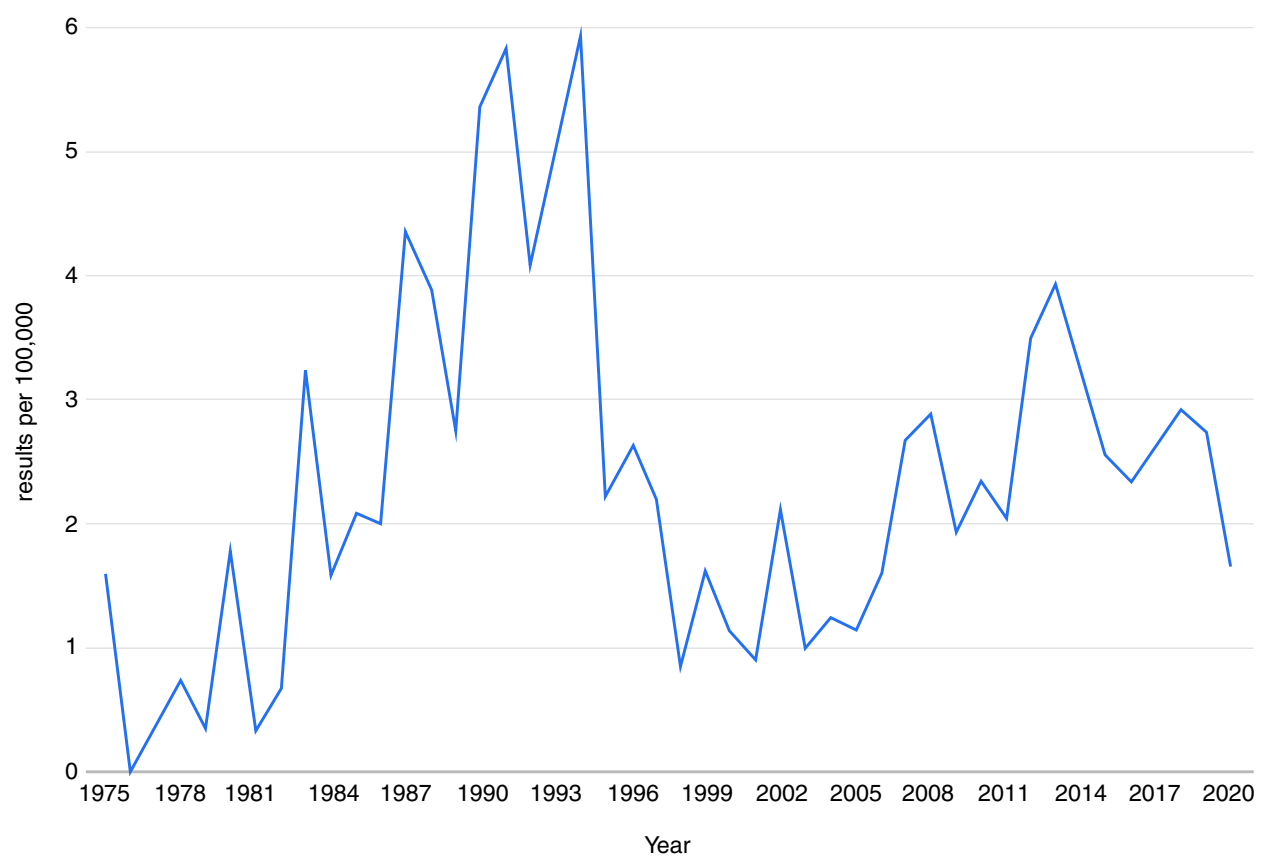

Figure 3 Temporal trends in publications on prosthetic devices for $A C L$ reconstruction.

who described internal brace augmentation in 2015, Murray et $a l^{51}$ and Kiapour et $a l^{52}$ who described the bridge-enhanced ACL repair technique in 2016, and Achtnich et al ${ }^{53}$ who described ACL repair suture fixation in 2016. In reviewing the older literature, Sherman $e t a l^{46}$ and van der List $e t a l^{54}$ reported excellent outcomes for patients with proximal ACL tears. Additionally, higher resolution MRI can now provide more accurate tear location and type delineation, better identifying patients who might benefit from primary ACL repair. Recent systematic reviews ${ }^{55-57}$ suggest that primary ACL repair may be efficacious for younger patients with skeletal immaturity who present acutely with proximal tears. However, the overall complication/reoperation rate $(15 \%)$ in addition to more common passive knee range of motion impairments suggest that its general use remains inferior to ACL reconstruction. More clinical documentation is needed before widely adopting these techniques. National multicentre registries need to be established to closely follow these patients.

\section{Prosthetic devices for $A C L$ reconstruction}

We identified 647 citations (figure 3).

During the early part of the twentieth century Hope abounded for the development of a prosthetic ACL with goals of implanting a strong, 'off the shelf' construct that allowed rapid rehabilitation and early return to activities. In 1907, Lange described the cases of four patients who received intra-articular artificial silk ACLs in conjunction with extra-articular semitendinosus and semimembranosus tendon augmentation. ${ }^{58} 59$ In 1918, Alwyn Smith ${ }^{60}$ reported using silk material to repair the ACL, which at 3 months resulted in synovitis that necessitated its removal from the joint. In 1949, Ruther ${ }^{61}$ reported failure for ACL reconstruction using Supramid, a polyamide derivative. In 1979, Woods et $a l^{62}$ and others reported breakage at just over 1 year postsurgery for ACL reconstruction performed with Proplast: polytetrafluoroethylene (PTFE) with embedded carbon or aluminium oxide fibres. In treating patients with multiply operated, unstable knees, Ahlfeld et $a l^{63}$ reported superior objective and subjective results among patients who received the expanded PTFE prosthesis compared with the conventional Proplast device at 24 months postsurgery.

The underachieved Hope of the early twentieth century led to the Inflation of the 1980s with a progression of biomaterials with synthetics rapidly growing in popularity for ACL reconstruction in three main forms: grafts that enabled tissue vascularisation and maturation, permanent prosthetic replacement without soft tissue ingrowth, and augmentation in the form of a stent or graft wrap for protection through the revascularisation and tissue ingrowth periods. Following this, in somewhat rapid succession, in 1978, Jenkins ${ }^{64}$ reported on carbon fibre based ACL graft development to serve as a temporary implant promoting fibroblast ingrowth and collagen production. To reduce carbon wear particle development this construct was modified by Alexander et $a l^{65}$ in 1983 to include a polylactic acid and polycaprolactone coating. Strover ${ }^{66}$ later described the Activated Biological Composite prosthetic (ABC, Surgicraft, Redditch, UK) which blended carbon (for fibrogenesis) and polyester (for durability) fibres. In 1980, Kennedy et $a l^{67} 68$ introduced a band-like polypropylene braid, the ligament augmentation device (LAD, 3M, St Paul, Minnesota, USA), to protect the vulnerable autologous graft during remodelling. The LAD was implanted using the Macintosh/Marshall ACL reconstruction technique. In 1985 the Gore-Tex prosthesis made of looped PTFE was developed by Gore and associates, demonstrating an ultimate tensile strength three times that of the human ACL. ${ }^{69}$ Following a similar principle of graft augmentation, Mansat ${ }^{70}$ described the Proflex ligament (Protek, Bern, Switzerland), a polyester stent used to reinforce a patellar tendon autograft, with the transplant fixed in a femoral tunnel and the artificial ligament attached over the top. Inspired by previous vascular implant success, the polyester strip based Stryker Dacron ligament prosthesis (Stryker, Kalamazoo, Michigan, USA) was developed in $1988 .{ }^{71}$ In 1992 , based 
on polyester composite meshes, the Leeds-Keio prosthesis was developed (Xiros, formerly Neoligaments, Leeds, England) to serve as a soft tissue ingrowth scaffold. With this device some have reported neoligamentous tissue ingrowth ${ }^{72}$ while others have found it to behave as a permanent prosthesis. ${ }^{73}$

Because of poor outcomes and high mid-term and long-term complication rates ${ }^{74}{ }^{75}$ Disillusion for prosthetic ACL development occurred in the 1990s. Prosthetic implant use was associated with intra-articular debris generation from osseous surface abrasion, reactive synovitis and effusion, mechanical fibre fatigue with instability and failure, osteolysis, and premature osteoarthritis development. Chronic synovitis predisposed to infection. Issues such as these were identified in 1988 for the Gore-Tex prosthesis, ${ }^{76-79}$ in 1991 for the Leeds-Keio prosthesis ${ }^{73} 8081$ and in 1992 for the Stryker Dacron ligament prosthesis. ${ }^{82-84}$ In 1992, synovitis characterised by foreign body giant cells and macrophages in the surrounding tissue,${ }^{85}$ a weak graft interface and autogenous tissue stress-shielding were identified with the LAD. ${ }^{86} \mathrm{~A}$ randomised controlled trial failed to reveal any benefit for LAD use.$^{87}$ From 1993 onwards, similar issues were identified for the $\mathrm{ABC}$ prosthesis. ${ }^{88}$ Poor results were confirmed in a systematic review published in $2015^{75}$ and in a long-term follow-up study published in $2010{ }^{89}$ The Eclipse of ACL prosthesis development occurred in the 1990s as poor long-term results suggested that they were no longer suitable for ACL reconstruction.

Associated with promotions to achieve more rapid and spectacular mobility and strength by avoiding donor site morbidity, the Rebirth of ACL prosthetic devices occurred in the 2000s. In 2000 the Ligament Advanced Reinforcement System prosthesis was developed in France. It consists of polyethylene terephthalate (PET) fibres with an intraosseous component to promote bony ingrowth and an intra-articular part with fibres designed to be more fatigue and wear resistant to natural ligamentous torsion. Lavoie et $a l^{90}$ first reported its clinical use. Since this time there have been conflicting results reported ${ }^{9192}$ followed by various clinical applications, including posterior cruciate ligament reconstruction, ${ }^{93}$ multiligament reconstruction following knee dislocation, ${ }^{94}$ acromioclavicular joint separation $^{95}$ and hip abductor tendon repair. ${ }^{96}$ At 6 years postsurgery failure rates of $33 \%$ have been reported for ACL reconstruction. ${ }^{92}$ In 2006, with the addition of a radiofrequency procedure a second generation polyester composite Leeds-Keio prosthesis was developed to provide better tissue ingrowth capability. ${ }^{97}$ Ongoing research in China on PET fibres is studying how prosthesis ligamentisation can be enhanced ${ }^{98}$ to improve biocompatibility, thereby promoting better cell adhesion/proliferation and osteointegration. Hydroxyapatite ${ }^{99}$ and silk fibroin ${ }^{100} 101$ coatings are being studied for enhanced ligamentisation. Currently, the primary obstacle to successful prosthetic ACL reconstruction is longevity, as autologous graft sources provide more durable replacements. Synthetic ligaments with no abrasion, no immune reactions and that enable significant tissue ingrowth have not been developed.

\section{Study limitations}

This study has several important limitations. The study methods that were used quantitatively analysed specific topics as described a priori. A citation analysis was performed based on study titles and abstract reviews. However, content analysis of each study was not performed and there were no exclusion criteria. Therefore, even non-clinical and basic science studies on the selected topics were included. Also, no distinction was made between original articles and review papers. Also, journal impact factor of the articles that contributed to this study were not assessed. Use of the Thomson Reuters Journal Citation Report which is commonly used in bibliometric analysis would have enabled selection of articles that were published solely in higher impact journals. This would have enabled concurrent assessment of study quality in addition to volume and rate of publication. The studies that contributed to this analysis were found exclusively using the PubMed search engine to review the MEDLINE database. Other databases such as Embase and Web of Science were not included. The MEDLINE database cites studies from the US National Library of Medicine at the National Institutes of Health. The USA is the largest single nation contributor to scientific research, however, studies from other databases may have been omitted. The statistical methodology that was used only represented descriptive global research trend analysis based on selected topics. It has shown a cyclic nature of publications only. It remains unclear how much this research has affected current clinical practices over the years. Also, the primary author solely screened each study. Therefore, potential exists for selection bias risk. Lastly, the trend timing figures are based on publication date. Actual research performance and report development likely occurred 6-12 months prior to publication.

\section{Lessons learnt}

Rather than rushing to a new surgical technique, history has repeatedly shown that knee surgeons and orthopaedic surgeons in general should adopt a more systematic stepwise approach to investigating content related to innovative knee surgical procedures. This approach should give ample respect and a more humble attitude to the need for understanding surgical anatomy and histology, biomechanical studies and well-designed clinical trials.

Three general tendencies were observed in figure graphics: (1) Initial hope-inflation and rebirth trend peaks occurred after a minimum of 20 years between phases; (2) The initial hopeinflation and rebirth phase trend peak interval for anterolateral knee instability seems to be approximately 35 years; and (3) Rebirth trend peak slope trajectories for each topic seemed to display more rapid and stronger rise times than the initial trend peak slope trajectories. As the literature review spans only 45 years, it is important to emphasise that these findings solely represent trends of interest, and not firm, evidence-based conclusions. We propose that this observation warrants further study. What combination of events catalysed these rebirth trajectories? Did this occur because key research evidence had better established a more solid path to renewed topic interest?

Given the limitations of the day many of these 'old ideas' may have been underestimated or misunderstood at first glance leading to their initial Eclipse. This does not mean that they could not be revisited and improved on. Innovative thoughts and original discoveries often arise from surgeons outside of academic centres. Many times, these 'doers and true thinkers' were orthopaedic surgeons and sports medicine practitioners such as Lemaire, ${ }^{3}$ Macintosh, ${ }^{4}$ and Losee ${ }^{6}$ who learnt by doing, spending long days in the operating theatre. They meticulously studied and learnt from each surgical case taking notes, creating drawings and taking photographs. From this they discovered unusual or unique anatomical situations and confirmed new soft tissue trauma pathoanatomy patterns and healing responses in the process.

Remembering is important! To better capture how historical surgical procedures and techniques might be of benefit today 
given the resources available in the world we live in, it may be beneficial for young surgeons to review the work of previous generation surgeons and scientists through more contemporary eyes. We should also better identify when a particular surgical procedure has repeatedly failed despite ample amounts of hope and enthusiasm. In cases such as these we need to be more vigilant to ensure that young knee surgeons do not get seduced again by 'new discoveries' that have proven time and time again to fail. As George Santayana, a Spanish-born American author and philosopher of the late nineteenth and early twentieth centuries stated, 'Those who cannot remember the past are condemned to repeat it ${ }^{102}$ Studying history is necessary to avoid repeating past mistakes. To this we only add that it may suffice to reference key historical works, and to revisit surgical procedures in the morgue and in laboratories with fresh, contemporary eyes.

\section{CONCLUSIONS}

Based on this analysis we recommend that knee surgeons become more aware of the lessons of history. Important lessons can be learnt from both the past successes and failures of our predecessors. If we do not learn from their failures, we will be likely to repeat them, placing patients at an unjustified risk. From past successes we can build on previous good ideas and important discoveries that have shown themselves to be tried and true over time. The cycle phenomenon that was observed by the senior author (RPJ) suggests that knee surgeons need to better balance early enthusiasm and hope for innovative surgical practice efficacy with the guidance of scientific rigour derived evidence and history. History suggests that when past surgical practices have failed, their 'rediscovery' was consistently associated with a better understanding of the vital interdependence between ACL anatomy, tissue composition, biomechanics and healing processes. Resar stated that healthcare clinicians successfully apply proven medical evidence less than $80 \%$ of the time. Knee surgeons should remember to approach all innovations with care and patience, as the effects of good and bad surgical practices may take years to become manifest. This 'wait and see' approach blended with the systematic acquisition of scientific evidence and reflective clinical practice might be the best path to improving patient outcomes.

Contributors RPJ conceived the idea and supervised the manuscript. RM designed the bibliometric analysis, undertook the literature search, collected data and prepared the manuscript. JN was highly involved in writing and editing this manuscript.

Funding The authors have not declared a specific grant for this research from any funding agency in the public, commercial or not-for-profit sectors.

Competing interests None declared.

Patient consent for publication Not required.

Provenance and peer review Commissioned; externally peer reviewed.

Data availability statement Data are available upon request;

\section{REFERENCES}

1 Williams A. Editorial commentary: the anterolateral ligament: the emperor's new clothes? Arthroscopy 2018;34:1015-21.

2 Sperr E. Pubmed by year, 2016. Available: http://esperr.github.io/pubmed-by-year/

3 Lemaire M. Ruptures anciennes Du ligament croisé antérieur Du genou. J Chir 1967;93:311-20.

4 Macintosh DDT. Lateral substitution reconstruction. in proceedings of the Canadian orthopaedic association. JBone Joint Surg 1976;142:58-B.

5 Hughston JC, Andrews JR, Cross MJ, et al. Classification of knee ligament instabilities. Part II. the lateral compartment. J Bone Joint Surg Am 1976;58:173-9.

6 Losee RE, Johnson TR, Southwick WO. Anterior subluxation of the lateral tibial Plateau. A diagnostic test and operative repair. J Bone Joint Surg Am 1978;60:1015-30.
7 Norwood LA, Andrews JR, Meisterling RC, et al. Acute anterolateral rotatory instability of the knee. J Bone Joint Surg Am 1979;61:704-9.

8 Ellison AE. Distal iliotibial-band transfer for anterolateral rotatory instability of the knee. J Bone Joint Surg Am 1979;61:330-7.

9 Andrews JR, Sanders RA, Morin B. Surgical treatment of anterolateral rotatory instability. A follow-up study. Am J Sports Med 1985;13:112-9.

10 Zarins B, Rowe CR. Combined anterior cruciate-ligament reconstruction using semitendinosus tendon and iliotibial tract. J Bone Joint Surg Am 1986;68:160-77.

11 Terry GC, Hughston JC, Norwood LA. The anatomy of the iliopatellar band and iliotibial tract. Am J Sports Med 1986;14:39-45.

12 Lerat JL, Dupré La Tour L, Herzberg G, et al. [Review of 100 patients operated on for chronic anterior laxity of the knee by a procedure derived from the Jones and Maclntosh methods. Value of dynamic radiography for the objective analysis of the results]. Rev Chir Orthop Reparatrice Appar Mot 1987;73 Suppl 2:201-4.

13 Irvine GB, Dias JJ, Finlay DB. Segond fractures of the lateral tibial condyle: brief report. J Bone Joint Surg Br 1987;69:613-4.

14 Neyret P, Palomo JR, Donell ST, et al. Extra-articular tenodesis for anterior cruciate ligament rupture in amateur skiers. Br J Sports Med 1994;28:31-4.

15 Strum GM, Fox JM, Ferkel RD, et al. Intraarticular versus intraarticular and extraarticular reconstruction for chronic anterior cruciate ligament instability. Clin Orthop Relat Res 1989;\&NA:188-98.

16 O'Brien SJ, Warren RF, Wickiewicz TL, et al. The iliotibial band lateral sling procedure and its effect on the results of anterior cruciate ligament reconstruction. Am J Sports Med 1991;19:21-5.

17 Engebretsen L, Lew WD, Lewis JL, et al. The effect of an iliotibial tenodesis on intraarticular graft forces and knee joint motion. Am J Sports Med 1990;18:169-76.

18 Draganich LF, Reider $B$, Ling $M$, et al. An in vitro study of an intraarticular and extraarticular reconstruction in the anterior cruciate ligament deficient knee. Am J Sports Med 1990;18:262-6.

19 Roth JH, Kennedy JC, Lockstadt H, et al. Intra-Articular reconstruction of the anterior cruciate ligament with and without extra-articular supplementation by transfer of the biceps femoris tendon. J Bone Joint Surg Am 1987;69:275-8.

20 Dodds AL, Gupte CM, Neyret P, et al. Extra-Articular techniques in anterior cruciate ligament reconstruction. J Bone Joint Surg Br 2011;93-B:1440-8.

21 Vincent J-P, Magnussen RA, Gezmez F, et al. The anterolateral ligament of the human knee: an anatomic and histologic study. Knee Surg Sports Traumatol Arthrosc 2012;20:147-52

22 Tanaka M, Vyas D, Moloney G, et al. What does it take to have a high-grade pivot shift? Knee Surg Sports Traumatol Arthrosc 2012;20:737-42.

23 Claes S, Vereecke E, Maes M, et al. Anatomy of the anterolateral ligament of the knee. J Anat 2013;223:321-8.

24 Kittl C, El-Daou H, Athwal KK, et al. The role of the anterolateral structures and the $\mathrm{ACL}$ in controlling laxity of the intact and $\mathrm{ACL}-$ Deficient knee. Am J Sports Med 2016;44:345-54.

25 Caterine S, Litchfield R, Johnson M, et al. A cadaveric study of the anterolateral ligament: re-introducing the lateral capsular ligament. Knee Surg Sports Traumatol Arthrosc 2015:23:3186-95.

26 Helito CP, Bonadio MB, Gobbi RG, et al. Combined intra- and extra-articular reconstruction of the anterior cruciate ligament: the reconstruction of the knee anterolateral ligament. Arthrosc Tech 2015;4:e239-44.

27 Smith JO, Yasen SK, Lord B, et al. Combined anterolateral ligament and anatomic anterior cruciate ligament reconstruction of the knee. Knee Surg Sports Traumatol Arthrosc 2015;23:3151-6.

28 Sonnery-Cottet B, Daggett M, Helito CP, et al. Combined anterior cruciate ligament and anterolateral ligament reconstruction. Arthrosc Tech 2016;5:e1253-9.

29 Wagih AM, Elguindy AMF. Percutaneous reconstruction of the anterolateral ligament of the knee with a polyester tape. Arthrosc Tech 2016;5:e691-7.

30 Mathew M, Dhollander A, Getgood A. Anterolateral ligament reconstruction or extraarticular tenodesis. Clin Sports Med 2018;37:75-86.

31 Palmer I. On the injuries to the ligaments of the knee joint: a clinical study. 1938. Clin Orthop Relat Res 2007;454:282.

32 O'Donoghue DH. Surgical treatment of fresh injuries to the major ligaments of the knee. J Bone Joint Surg Am 1950;32 A:721-38.

33 England RL. Repair of the ligaments about the knee. Orthop Clin North Am 1976:7:195-204

34 Feagin JA, Curl WW. Isolated tear of the anterior cruciate ligament: 5-year follow-up study. Am J Sports Med 1976;4:95-100.

35 Maclntosh DL. A follow-up study and eventuation of over-the-top repair of acute tears of the anterior cruciate ligament. J Bone Jt Surg 1977;59:511.

36 Marshall JL, Warren RF, Wickiewicz TL, et al. The anterior cruciate ligament: a technique of repair and reconstruction. Clin Orthop Relat Res 1979;143:97-106.

37 Lysholm J, Gillquist J, Liljedahl SO. Long-term results after early treatment of knee injuries. Acta Orthop Scand 1982;53:109-18.

38 Warren RF. Primary repair of the anterior cruciate ligament. Clin Orthop Relat Res 1983:65-70.

39 Odensten M, Lysholm J, Gillquist J. Suture of fresh ruptures of the anterior cruciate ligament. A 5-year follow-up. Acta Orthop Scand 1984;55:270-2. 
40 Weaver JK, Derkash RS, Freeman JR, et al. Primary knee ligament repair revisited. Clin Orthop Relat Res 1985;199:185-91.

41 Sherman MF, Bonamo JR. Primary repair of the anterior cruciate ligament. Clin Sports Med 1988;7:739-50.

42 Engebretsen L, Benum PÅL, Sundalsvoll S. Primary suture of the anterior cruciate ligament a 6-year follow-up of 74 cases. Acta Orthop Scand 1989;60:561-4.

43 Feagin JA, Curl WW. Isolated tear of the anterior cruciate ligament: five-year followup study. J Orthop Sports Phys Ther 1990;12:232-6.

44 Feagin JA, Curl WW. Isolated tear of the anterior cruciate ligament: 5-year followup study. Clin Orthop Relat Res 1996;325:4-9.

45 Kaplan N, Wickiewicz TL, Warren RF. Primary surgical treatment of anterior cruciate ligament ruptures. A long-term follow-up study. Am J Sports Med 1990;18:354-8.

46 Sherman MF, Lieber L, Bonamo JR, et al. The long-term followup of primary anterior cruciate ligament repair. defining a rationale for augmentation. Am J Sports Med 1991;19:243-55.

47 Grøntvedt T, Engebretsen L, Benum P, et al. A prospective, randomized study of three operations for acute rupture of the anterior cruciate ligament. fiveyear follow-up of one hundred and thirty-one patients. J Bone Joint Surg Am 1996;78:159-69.

48 Grøntvedt T, Engebretsen L. Comparison between two techniques for surgical repair of the acutely torn anterior cruciate ligament. A prospective, randomized follow-up study of 48 patients. Scand J Med Sci Sports 1995;5:358-63.

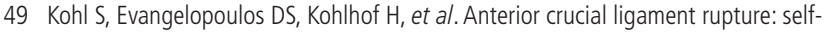
healing through dynamic intraligamentary stabilization technique. Knee Surg Sports Traumatol Arthrosc 2013;21:599-605

50 Biercevicz AM, Proffen BL, Murray MM, et al. T2* relaxometry and volume predict semi-quantitative histological scoring of an ACL bridge-enhanced primary repair in a porcine model. J Orthop Res 2015;33:1180-7.

51 Murray MM, Flutie BM, Kalish LA, et al. The Bridge-Enhanced Anterior Cruciate Ligament Repair (BEAR) Procedure: an early feasibility cohort study. Orthop J Sports Med 2016:4:2325967116672176.

52 Kiapour AM, Fleming BC, Murray MM. Biomechanical outcomes of bridge-enhanced anterior cruciate ligament repair are influenced by sex in a preclinical model. Clin Orthop Relat Res 2015;473:2599-608.

53 Achtnich A, Herbst E, Forkel $\mathrm{P}$, et al. Acute proximal anterior cruciate ligament tears: outcomes after arthroscopic suture anchor repair versus anatomic single-bundle reconstruction. Arthroscopy 2016:32:2562-9.

54 van der List JP, DiFelice GS. Primary repair of the anterior cruciate ligament: a paradigm shift. Surgeon 2017;15:161-8.

55 van Eck CF, Limpisvasti O, ElAttrache NS. Is there a role for internal bracing and repair of the anterior cruciate ligament? A systematic literature review. Am J Sports Med 2018:46:2291-8.

56 Nwachukwu BU, Patel BH, Lu Y, et al. Anterior cruciate ligament repair outcomes: an updated systematic review of recent literature. Arthroscopy 2019;35:2233-47.

57 Ahmad SS, Schreiner AJ, Hirschmann MT, et al. Dynamic intraligamentary stabilization for ACL repair: a systematic review. Knee Surg Sports Traumatol Arthrosc 2019;27:13-20.

58 Schindler OS. Surgery for anterior cruciate ligament deficiency: a historical perspective. Knee Surg Sports Traumatol Arthrosc 2012;20:5-47.

59 Mascarenhas R, MacDonald PB. Anterior cruciate ligament reconstruction: a look at prosthetics--past, present and possible future. Mcgill J Med 2008;11:29-37.

60 Smith SA, Alwyn Smith S. The diagnosis and treatment of injuries to the crucial ligaments. Br J Surg 1918;6:176-89.

61 Rüther H. Die Verwendung von Supramid in Der operativen Orthopädie. Z Orthop 1949:78:161-9.

62 William Woods G, Homsy CA, Prewitt JM, et al. Proplast leader for use in cruciate ligament reconstruction. Am J Sports Med 1979;7:314-20.

63 Ahlfeld SK, Larson RL, Collins HR. Anterior cruciate reconstruction in the chronically unstable knee using an expanded polytetrafluoroethylene (PTFE) prosthetic ligament. Am J Sports Med 1987; 15:326-30.

64 Jenkins $\mathrm{DH}$. The repair of cruciate ligaments with flexible carbon fibre. A longer term study of the induction of new ligaments and of the fate of the implanted carbon. J Bone Joint Surg Br 1978;60-B:520-2.

65 Alexander H, Weiss AB, Parsons JR. Absorbable polymer-filamentous carbon composites--a new class of tissue scaffolding materials. Aktuelle Prob/ Chir Orthop 1983;26:78-91.

66 Strover A. The ABC ligament for chronic anterior cruciate ligament insufficiency. In: Aichroth PM, Cannon WD, Patel DV, eds. Knee surgery: current practice, 1992: 281-97.

67 Kennedy JC. Application of prosthetics to anterior cruciate ligament reconstruction and repair. Clin Orthop Relat Res 1983:125-8.

68 Kennedy JC, Roth JH, Mendenhall HV, et al. Presidential address. intraarticular replacement in the anterior cruciate ligament-deficient knee. Am J Sports Med 1980:8:1-8.

69 Bolton CW, Bruchman WC. The GORE-TEX expanded polytetrafluoroethylene prosthetic ligament. An in vitro and in vivo evaluation. Clin Orthop Relat Res 1985;196:202-13.
70 Allard M. The use of Proflex in the repair of anterior cruciate ligament lesions. In: Müller W, Hackenbruch W, eds. Surgery and Arthroscopy of the knee Springer. Berlin, Heidelberg, 1988: 225-34.

71 Lukianov AV, Richmond JC, Barrett GR, et al. A multicenter study on the results of anterior cruciate ligament reconstruction using a Dacron ligament prosthesis in "salvage" cases. Am J Sports Med 1989;17:380-6.

72 Fujikawa K, Iseki F, Seedhom BB. Arthroscopy after anterior cruciate reconstruction with the Leeds-Keio ligament. J Bone Joint Surg Br 1989;71-B:566-70.

73 Macnicol MF, Penny ID, Sheppard L. Early results of the Leeds-Keio anterior cruciate ligament replacement. J Bone Joint Surg Br 1991;73-B:377-80.

74 Guidoin M-F, Marois Y, Bejui J, et al. Analysis of retrieved polymer fiber based replacements for the ACL. Biomaterials 2000;21:2461-74.

75 Batty LM, Norsworthy CJ, Lash NJ, et al. Synthetic devices for reconstructive surgery of the cruciate ligaments: a systematic review. Arthroscopy 2015;31:957-68.

76 Paulos LE, Rosenberg TD, Grewe SR, et al. The GORE-TEX anterior cruciate ligament prosthesis. A long-term followup.. Am J Sports Med 1992;20:246-52.

77 Fukubayashi T, Ikeda K. Follow-Up study of Gore-Tex® artificial Ligament-Special emphasis on tunnel osteolysis. J Long Term Eff Med Implants 2000;10:12-77.

78 Glousman R, Shields C, Kerlan R, et al. Gore-Tex prosthetic ligament in anterior cruciate deficient knees. Am J Sports Med 1988;16:321-6.

79 Woods GA, Indelicato PA, Prevot TJ. The Gore-Tex anterior cruciate ligament prosthesis. Two versus three year results. Am J Sports Med 1991;19:48-55.

80 Denti M, Bigoni M, Dodaro G, et al. Long-Term results of the Leeds-Keio anterior cruciate ligament reconstruction. Knee Surg Sports Traumatol Arthrosc 1995:3:75-7

81 Schindhelm K, Rogers GJ, Milthorpe BK, et al. Autograft and Leeds-Keio reconstructions of the ovine anterior cruciate ligament. Clin Orthop Relat Res 1991:278-93

82 Wredmark T, Engström B. Five-Year results of anterior cruciate ligament reconstruction with the Stryker Dacron high-strength ligament. Knee Surg Sports Traumatol Arthrosc 1993;1:71-5.

83 Richmond JC, Manseau CJ, Patz R, et al. Anterior cruciate reconstruction using a Dacron ligament prosthesis. Am J Sports Med 1992;20:24-8.

84 Barrett GR, Line LL, Shelton WR, et al. The Dacron ligament prosthesis in anterior cruciate ligament reconstruction. Am J Sports Med 1993:21:367-73.

85 Yamamoto $\mathrm{H}$, Ishibashi $\mathrm{T}$, Muneta $\mathrm{T}$, et al. Effusions after anterior cruciate ligament reconstruction using the ligament augmentation device. Arthroscopy 1992;8:305-10

86 Barrett GR, Field LD. Comparison of patella tendon versus patella tendon/Kennedy ligament augmentation device for anterior cruciate ligament reconstruction: study of results, morbidity, and complications. Arthroscopy 1993;9:624-32.

87 Moyen BJ, Jenny JY, Mandrino AH, et al. Comparison of reconstruction of the anterior cruciate ligament with and without a Kennedy ligament-augmentation device. A randomized, prospective study. J Bone Joint Surg Am 1992;74:1313-9.

88 Mody BS, Howard L, Harding ML, et al. The ABC carbon and polyester prosthetic ligament for ACL-deficient knees. early results in 31 cases. J Bone Joint Surg $\mathrm{Br}$ 1993;75:818-21

89 Ventura A, Terzaghi C, Legnani C, et al. Synthetic grafts for anterior cruciate ligament rupture: 19-year outcome study. Knee 2010;17:108-13.

90 Lavoie P, Fletcher J, Duval N. Patient satisfaction needs as related to knee stability and objective findings after $A C L$ reconstruction using the LARS artificial ligament. Knee 2000;7:157-63.

91 Sun J, Wei X-C, Li L, et al. Autografts vs Synthetics for cruciate ligament reconstruction: a systematic review and meta-analysis. Orthop Surg 2020;12:378-87.

92 Tulloch SJ, Devitt BM, Porter T, et al. Primary ACL reconstruction using the LARS device is associated with a high failure rate at minimum of 6-year follow-up. Knee Surg Sports Traumatol Arthrosc 2019;27:3626-32.

93 Chiang L-Y, Lee C-H, Tong K-M, et al. Posterior cruciate ligament reconstruction implemented by the Ligament Advanced Reinforcement System over a minimum follow-up of 10 years. Knee 2020;27:165-72.

94 Ranger P, Senay A, Gratton GR, et al. LARS synthetic ligaments for the acute management of 111 acute knee dislocations: effective surgical treatment for most ligaments. Knee Surg Sports Traumatol Arthrosc 2018;26:3673-81.

95 Ochen Y, Beks RB, Emmink BL, et al. Surgical treatment of acute and chronic AC joint dislocations: five-year experience with conventional and modified LARS fixation by a single surgeon. J Orthop 2020;17:73-7.

96 Ebert JR, Brogan K, Janes GC. A prospective 2-year clinical evaluation of augmented hip abductor tendon repair. Orthop J Sports Med 2020;8:232596711989788.

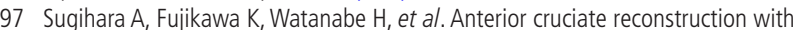
bioactive Leeds-Keio ligament (LKII): preliminary report. J Long Term Eff Med Implants 2006;16:41-9.

$98 \mathrm{Li} \mathrm{H}$, Chen S. Biomedical coatings on polyethylene terephthalate artificial ligaments. J Biomed Mater Res A 2015:103:839-45.

99 Cai J, Ai C, Chen J, et al. Biomineralizaion of hydroxyapatite on polyethylene terephthalate artificial ligaments promotes graft-bone healing after anterior cruciate ligament reconstruction: an in vitro and in vivo study. J Biomater App/ 2020;35:193-204. 
100 Zhi Y, Jiang J, Zhang P, et al. Silk enhances the ligamentization of the polyethylene terephthalate artificial ligament in a canine anterior cruciate ligament reconstruction model. Artif Organs 2019;43:E94-108.
101 Jiang J, Ai C, Zhan Z, et al. Enhanced fibroblast cellular ligamentization process to polyethylene terepthalate artificial ligament by silk fibroin coating. Artif Organs 2016;40:385-93.

102 Santayana G. The Life of Reason or The Phases of Human Progress: Reason in Common Sense. New York, Scribner's, 1920: 284. 